\title{
Artigos
}

\section{Avaliação das políticas de educação infantil no Brasil: avanços e retrocessos}

Resumo: $O$ artigo analisa as principais políticas educacionais estabelecidas para a educação básica no Brasil, no século XXI, com repercussão na educação infantil ou especialmente destinada a ela. Avalia a implementação das mesmas sob três critérios: a democratização do acesso, a qualidade do atendimento e o estímulo à gestão democrática, analisando as repercussões positivas e negativas das mesmas.

Palavras-chave: Política Educacional. Educação Básica. Educaçãolnfantil. AvaliaçãoEducacional.

\section{Evaluation of child education policies in Brazil: advances and setbacks}

Abstract: This article analyzes the main educational policies established for basic education in Brazil, in the 21 st century, with repercussions inchild education or specially destined for it. It evaluates their implementation under three criteria: the democratization of access, the quality of care and the stimulus to democratic management, analyzing the positive and negative repercussions of them.

Keywords: Educational Policy. Basic Education. Early Childhood Education. Educational Evaluation.

' Doutora em Educação pela Universidade de São Paulo. Professora Titular Sênior da Faculdade de Educação da USP. Presidente da Associação Nacional de Pesquisa em Financiamento da Educação (FINEDUCA). Pesquisadora na área de Política Educacional, Planejamento e Avaliação Educacional, Financiamento da Educação Básica e Educação Popular. E-mail: liselaro@usp.br 


\section{Considerações iniciais}

$\mathrm{H}$

á três critérios de avaliação de políticas públicas que são consenso na área de educação: 1) a

democratização do acesso, enquanto condição de realização do direito à educação de todos e

todas; 2) a qualidade do atendimento, que implica na existência de projeto pedagógico consistente e condições de trabalho dos profissionais do magistério (salário, jornada de trabalho, número de alunos por turma, materiais e equipamentos diversificados) pertinentes à função educacional, como condição de permanência dos alunos no sistema de ensino, e 3) a gestão democrática, princípio educacional e condição de participação dos usuários na elaboração das propostas de políticas públicas, seu acompanhamento e sua avaliação. Em função disso analisaremos as políticas educacionais sob a luz dessas variáveis.

A Constituição Federal de 1988 (CF/88), em seu artigo 227, determina que

É dever da família, da sociedade e do Estado assegurar à criança, ao adolescente e ao jovem, com absoluta prioridade, o direito à vida, à saúde, à alimentação, à educação, ao lazer, à profissionalização, à cultura, à dignidade, ao respeito, à liberdade e à convivência familiar e comunitária, além de colocá-los a salvo de toda forma de negligência, discriminação, exploração, violência, crueldade e opressão. (BRASIL,1988)

A CF/88também garante que criança é um "ser de direitos" e que a educação infantil é direito do cidadão e dever do Estado, e deve ser oferecida numa perspectiva educacional. Isso se deu em resposta aos movimentos sociais em defesa das crianças. E, portanto, ela não é "obrigatória", mas direito das famílias e das crianças e não somente dos pais/ mães que trabalham fora de casa.

É importante observar que a educação infantil embora tenha mais de um século de história como cuidado e educação extradomiciliar, somente nos últimos anos foi reconhecida como direito da criança e das famílias e dever do Estado. A Lei de Diretrizes e Bases da Educação Nacional (Lei no. 9394/1996-LDB) estabeleceu a educação infantil como primeira etapa da educação básica, o que significou valorização importante desta etapa de ensino.

A LDB define a finalidade da educação infantil como "o desenvolvimento integral da criança de até cinco anos de idade em seus aspectos físico, psicológico, intelectual e social, complementando a ação da família e da comunidade" (Art. 29)

Para o Estatuto da Criança e do Adolescente (ECA - Lei 8069/1990) criança é a pessoa até doze anos de idade incompletos $\left(\right.$ Art. $2^{\circ}$ ), e goza de todos os direitos fundamentais inerentes à pessoa humana, "assegurando-se lhe todas as oportunidades e facilidades, a fim de lhes facultar o desenvolvimento físico, mental, moral, espiritual e social, em condições de liberdade e de dignidade" (Art. $3^{\circ}$ ).

Os direitos enunciados no ECA aplicam-se a todas as crianças,

sem discriminação de nascimento, situação familiar, idade, sexo, raça, etnia ou cor, religião ou crença, deficiência, condição pessoal de desenvolvimento e aprendizagem, condição econômica, ambiente social, região e local de moradia ou outra condição que diferencie as pessoas, as famílias ou a comunidade em que vivem (ECA, do Art. $3^{\circ}$, 2016).

A educação infantil deve ser atendida em creche ( 0 a 3 anos) e pré-escola (4 a 5 anos e 11 meses), ainda que muitos educadores defendam que as crianças de zero a 5 anos poderiam ser atendidas 
em uma só unidade, uma vez que essa separação de idades, só se sustenta para fins de adequação arquitetônica e pedagógica das instituições educacionais. Destaque-se que a inclusão da creche no capítulo da Educação da CF/88explicita a função eminentemente educativa desta, considerando parte intrínseca da mesma a função de cuidar. Essa inclusão constituiu um ganho na história da educação infantil em nosso país, com modificações positivas no atendimento educacional.

O Parecer do Conselho Nacional de Educação (CNE/CBE), n 20/2009, que deu origens às Diretrizes Curriculares Nacionais para a Educação Infantil afirma no seu histórico:

\begin{abstract}
Essa vinculação institucional diferenciada refletia uma fragmentação nas concepções sobre educação das crianças em espaços coletivos, compreendendo o cuidar como atividade meramente ligada ao corpo e destinada às crianças mais pobres, e o educar como experiência de promoção intelectual reservada aos filhos dos grupos socialmente privilegiados. Para além dessa especificidade, predominou ainda, por muito tempo, uma política caracterizada pela ausência de investimento público e pela não profissionalização da área. Em sintonia com os movimentos nacionais e internacionais, um novo paradigma do atendimento à infância - iniciado em 1959 com a Declaração Universal dos Direitos da Criança e do Adolescente e instituído no país pelo artigo 227 da Constituição Federal de 1988 e pelo Estatuto da Criança e do Adolescente (Lei $8.069 / 90)$ - tornou-se referência para os movimentos sociais de "luta por creche" e orientou a transição do entendimento da creche e pré-escola como um favor aos socialmente menos favorecidos para a compreensão desses espaços como um direito de todas as crianças à educação, independentemente de seu grupo social. (BRASIL, CNE. 2009)
\end{abstract}

No entanto, a democratização da oferta ainda que tenha crescido substantivamente, uma vez que em 2001 tínhamos cerca de um milhão de crianças de zero a três anos e onze meses matriculadas em creches, e, em 2015, as matriculas atingiram pouco mais de 3 milhões, demonstrando que esse crescimento, ainda que significativo representa pouco mais de $25 \%$ do atendimento nessa faixa etária. A tabela I mostra que o número estimado de crianças nessa faixa etária era, naquele ano, cerca de 11 milhões.

TABELA I: Democratização do acesso

\begin{tabular}{|c|c|c|c|}
\hline ANOS & 2001 & 2007 & 2015 \\
\hline Matrícula/creche(0 -3anose11meses) & 1.093 .347 & 1.575 .072 & 3.049 .072 \\
\hline População na faixa etária e \% & $13.882 .144(7,88 \%)$ & $\begin{array}{c}13.130 .205 \\
(12 \%)\end{array}$ & $\begin{array}{r}11.714 .289 \\
(25,87 \%)\end{array}$ \\
\hline Matrícula/pré-escola (4-5 anos) & 4.818 .803 & 4.818 .803 & 4.923 .158 \\
\hline $\begin{array}{c}\text { População na faixa etária de } 4 \text { a } 5 \text { anos de } \\
\text { idade e } \%\end{array}$ & $\begin{array}{l}49,7 \% \\
81,8 \%\end{array}$ & $\begin{array}{l}63,8 \% \\
83,1 \%\end{array}$ & $\begin{array}{l}68,1 \% \\
83,9 \%\end{array}$ \\
\hline
\end{tabular}

Fonte: Sinopses estatísticas, INEP/MEC.

Como se pode observar, quanto mais "velha" a criança, maior o atendimento, uma vez que o atendimento das crianças de 5 anos atingiu mais de $80 \%$ da faixa etária. As crianças de 4 anos, em 15 anos, saíram de $50 \%$ do atendimento para cerca de $70 \%$. Somente a faixa etária de zero a três anos, última etapa a ser valorizada educacionalmente é que ainda apresenta um atendimento mínimo para uma potencial demanda. 
Atente-se que, no Brasil, a participação das mulheres no mercado de trabalho cresce sistematicamente, ano a ano, desde a década de 1980, agravando a situação das crianças cujas famílias não contem com a existência de atendimento educacional. Além disso, com a modificação da organização familiar, é significativo o número de mulheres que são "cabeça de família", atingindo em algumas cidades brasileiras mais industrializadas, o percentual de $30 \%$ delas.

O Brasil, a partir dos anos de 1990 passou a admitir a importância do investimento em educação infantil, possibilitando um atendimento integral à sua formação e oferecendo melhores condições de desenvolvimento de sua criatividade, por meio de atividades lúdicas. Os economistas, por sua vez, têm defendido que o investimento na infância garante adultos melhores preparados para o mercado, o que, de certa forma, vem contribuindo para a admissão de sua importância e de aumento da oferta desse atendimento.

Essa nova dimensão da educação infantil colaborou, também, para a valorização do papel do profissional que atua com crianças de zero a cinco anos, com exigência de formação acadêmica derivada das novas responsabilidades sociais e educativas da creche. Assim, a formação de docentes para atuar na educação básica, nos termos da LDB,

(...) far-se-á em nível superior, em curso de licenciatura plena, admitida, como formação mínima para o exercício do magistério, na educação infantil e nos cinco primeiros anos do ensino fundamental, a oferecida em nível médio, na modalidade normal. (BRASIL. Art. 62,1996)

\section{Avanços das políticas para a educação infantil}

\section{Criação do Fundo de Manutenção e Desenvolvimento da Educação Básica e Valorização dos Profissionais de Educação (FUNDEB)}

O FUNDEB, criado pela Emenda Constitucional (EC) n $n^{\circ}$ 53/2006, é uma política de fundos que superou as limitações do Fundo de Manutenção e Desenvolvimento do Ensino Fundamental e Valorização do Magistério (FUNDEF), criado em 1996, pela EC no 14 pois, o mesmo privilegiava exclusivamente o ensino fundamental. $\mathrm{O}$ novo fundo incorpora todas as etapas e modalidades da educação básica e a educação infantil passou a ter direito ao uso desses fundos estaduais. É importante destacar que a área financeira do Governo não aceitava incluir a creche no FUNDEB e o movimento "Fraldas Pintadas", liderados pelo Movimento Interfóruns da Educação Infantil do Brasil (MIEIB) e pela Campanha Nacional pelo Direito à Educação, foi decisivo e sensibilizou o Congresso Nacional e o governo federal para a incorporação das crianças pequenas nesse financiamento.

Como o crescimento histórico do atendimento em creches sempre contou com entidades comunitárias ou privadas, as entidades comunitárias também foram autorizadas, desde que em convênios com a esfera pública, a fazer jus a esse financiamento. Pode-se afirmar que foi essa decisão a que permitiu a expansão significativa do número de crianças atendidas em creches, até o presente ano de 2017.

A maior cidade do Brasil, São Paulo, é um ótimo exemplo, pois possuía, em 2015, 369 creches sob responsabilidade da administração direta e 1350unidades em convênio com a Secretaria Municipal de Educação. Em 2014, 359 delas eram Centros de Educação Infantil (CEI) indiretos, ou seja, escolas públicas 
administradas pela iniciativa privada em convênio com a Prefeitura, e 991 eram creches comunitárias, havendo demanda inscrita, sem atendimento, de mais de 90.000 crianças (Fonte: PME/2015).

\section{Estabelecimento de Piso Nacional Salarial do Magistério (lei $\left.{ }^{\circ} .11 .738 / 2008\right)$}

Uma vitória importante para os profissionais da educação, particularmente os da educação infantil, foi o estabelecimento do piso nacional salarial do magistério, aprovado em 2008, proporcional a sua formação acadêmica. Esta Lei estabelecia, além do piso nacional, a obrigatoriedade de a jornada do professor prever $1 / 3$ de suas horas para atividades extraclasse. Essa vitória ainda é bastante discutida no país, pois, inicialmente alguns governadores de estado entraram com ação no Supremo Tribunal Federal (STF), alegando ser inconstitucional o estabelecimento de piso nacional, pois isso feria a autonomia dos estados. Cinco anos depois, o STF declarou legal a decisão sobre o estabelecimento de piso nacional, porém, até o ano de 2017 não julgou, no mérito, a legalidade do estabelecimento obrigatório de 1/3 da jornada de trabalho ser destinado a horas/atividades. Isso resultou em não cumprimento dessa exigência pela maioria dos estados e municípios brasileiros.

O valor do piso em 2017 corresponde a $\mathrm{R} \$ 2.298,80$, por quarenta horas semanais de trabalho e formação de nível médio. Apesar de estudos do próprio governo terem demonstrado que o salário do profissional do magistério é o mais baixo da escala de vencimentos dos outros funcionários públicos, mesmo assim, o piso nacional tem sido realizado, na prática, como teto salarial, pois como os Planos de Carreira não têm sido cumpridos, em número significativo de municípios, os professores ingressam com o piso e se aposentam, 25/30 anos depois com o mesmo salário, sendo o mesmo atualizado exclusivamente por tempo de serviço e parcela do percentual da inflação.

Mesmo assim, encontra-se superada a prática de municípios que pagavam metade do valor do salário mínimo oficial, alegando que a maioria das professoras tinham uma jornada de trabalho de $20 \mathrm{a}$ 22horas semanais e que, portanto, cumpriam as exigências trabalhistas estabelecidas na CF/88.

A existência de Piso Nacional também tem possibilitado que os sindicatos da categoria ingressem com ações na Justiça pedindo que o município ou estado seja obrigado a cumprir o estabelecido na Lei, na tentativa de garantir condições mínimas de trabalho ao magistério, sendo, em vários casos, atendidos.

\section{Estabelecimento da obrigatoriedade da educação básica de 4 a 17 anos de idade}

A EC nº. 59/2009 beneficiou a educação em três aspectos: excluindo a área da Educação da Desvinculação das Receitas da União (DRU), a partir de 2011, exigência que tem retirado, desde 1994, $20 \%$ dos recursos de impostos para o pagamento da dívida externa e serviços da dívida, o que, tem reduzido os $18 \%$ de recursos vinculados constitucionalmente para a manutenção e desenvolvimento do ensino, nos termos do art. 212 da CF/88, para 14,4\%.

O segundo aspecto positivo foi o estabelecimento da obrigatoriedade da educação básica dos 4 aos 17 anos para todas as crianças e adolescentes brasileiros. Houve uma discussão significativa sobre a inclusão das crianças de zero a três anos na obrigatoriedade escolar, e decidiu-se, ouvida a comunidade e 
associações nacionais, pela não extensão dessa obrigatoriedade para essa faixa etária. A EC n 59 previa a implantação gradativa dessa medida tendo estabelecido o ano de 2016 para o início dessa obrigatoriedade e ampliou, para toda a educação básica, o atendimento ao educando dos programas suplementares de material didático escolar, transporte, alimentação e assistência à saúde.

Outro aspecto importante que a EC 59 estabeleceu, com a mudança de redação do art. 214 da CF/88 e acréscimo do item VI foi a exigência de criação do sistema nacional de educação e de vinculação de proporção do produto interno bruto (PIB), como meta de aplicação de recursos públicos em educação. Diz ele

Art. 214. A lei estabelecerá o plano nacional de educação, de duração decenal, com o objetivo de articular o sistema nacional de educação em regime de colaboração e definir diretrizes, objetivos, metas e estratégias de implementação para assegurar a manutenção e desenvolvimento do ensino em seus diversos níveis, etapas e modalidades por meio de ações integradas dos poderes públicos das diferentes esferas federativas que conduzam a:

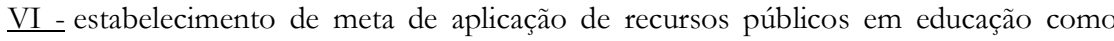
proporção do produto interno bruto (EMENDA CONSTITUCIONAL. 2009)

É verdade que, até 2017, a exigência de sistema nacional de educação não foi cumprida e apesar do estabelecimento na meta 20, do Plano Nacional de Educação, aprovado em junho de 2014 (Lei 13.005/2014), de 10\% do PIB para a educação, com a aprovação da EC n 95/2016, não só não houve aumento do percentual gasto, como os "cortes" nos recursos financeiros da educação contingenciamento de recursos, como é chamado - já atingem $20 \%$, do total dos gastos efetivamente realizados em 2014, ano de maior volume de recursos do governo federal para a educação, desde 2005.

\section{Diretrizes Curriculares Nacionais para a Educação Infantil}

As Diretrizes Curriculares Nacionais para a Educação Infantil, estabelecidas pela Resolução $\mathrm{CNE} / \mathrm{CEB} \mathrm{n}^{\circ}$ 05/2009, representam um avanço na definição dos seus objetivos, da concepção de seu currículo e das suas condições de funcionamento das instituições educacionais. Nele, a criança é definida como sujeito do processo de educação e

[...] centro do planejamento curricular, sujeito histórico e de direitos que, nas interações, relações e práticas cotidianas que vivencia, constrói sua identidade pessoal e coletiva, brinca, imagina, fantasia, deseja, aprende, observa, experimenta, narra, questiona e constrói sentidos sobre a natureza e a sociedade, produzindo cultura (BRASIL, 2009. Art. $\left.4^{\circ}\right)$.

O Parecer no 20/2009, anexo da Resolução CNE/CBE nº 05/2009, quando discute o conceito de currículo afirma

O currículo da Educação Infantil é concebido como um conjunto de práticas que buscam articular as experiências e os saberes das crianças com os conhecimentos que fazem parte do patrimônio cultural, artístico, científico e tecnológico. Tais práticas são efetivadas por meio de relações sociais que as crianças desde bem pequenas estabelecem com os professores e as outras crianças, e afetam a construção de suas identidades. Intencionalmente planejadas e permanentemente avaliadas, as práticas que estruturam o cotidiano das instituições de Educação Infantil devem considerar a integralidade e indivisibilidade das dimensões expressivo-motora, afetiva, cognitiva, linguística, ética, estética e sociocultural das crianças, apontar as experiências de aprendizagem que se espera promover junto às crianças e efetivar-se por meio de modalidades que assegurem as metas educacionais de seu projeto pedagógico. A gestão democrática da proposta curricular deve contar na sua elaboração, acompanhamento e avaliação tendo em vista o Projeto Político-Pedagógico da unidade educacional, com a 
participação coletiva de professoras e professores, demais profissionais da instituição, famílias, comunidade e das crianças, sempre que possível e à sua maneira (BRASIL. CNE. 2009).

Essa concepção de criança, de currículo e de organização escolar para a educação infantil supera as teorias pedagógicas, que consideravam a criança como "tábula rasa" ou desprovida de conhecimento e criatividade, só aguardando a idade apropriada para ser alfabetizada. A partir desta Resolução do CNE, as instituições de educação infantil assumiram-se como lócus adequado para o desenvolvimento educacional e de cuidados com a criança, redefinindo, positivamente, suas funções de educar e cuidar.

Os princípios básicos pelos quais a educação infantil deve se pautar foram assim definidos :a) Princípios éticos: procurando valorizar a autonomia, a responsabilidade, a solidariedade e o respeito ao bem comum, ao meio ambiente e às diferentes culturas, identidades e singularidade; b) Princípios políticos: que tratam dos direitos de cidadania, do exercício da criticidade e do respeito à ordem democrática; e c) Princípios estéticos: buscando a valorização da sensibilidade, da criatividade, da ludicidade e da diversidade de manifestações artísticas e culturais.

E para completar essa interessante visão sobre a criança e a educação infantil, o Parecer também afirma que

Uma atividade muito importante para a criança pequena é a brincadeira. Brincar dá à criança oportunidade para imitar o conhecido e para construir o novo, conforme ela reconstrói o cenário necessário para que sua fantasia se aproxime ou se distancie da realidade vivida, assumindo personagens e transformando objetos pelo uso que deles faz. [...] Além disso, à medida que o grupo de crianças interage, são construídas as culturas infantis (BRASIL. CNE. 2009).

\section{Aprovação do Plano Nacional de Educação (PNE) 2014/2024}

O IPNE 2001/2010 (Lei no 10.172/2001) havia estabelecido em relação à educação infantil a seguinte meta

Ampliar a oferta de educação infantil de forma a atender, em cinco anos, a 30\% da população de até 3 anos de idade e $60 \%$ da população de 4 a 6 anos (ou 4 e 5 anos) e, até o final da década, alcançar a meta de $50 \%$ das crianças de 0 a 3 anos e $80 \%$ das de 4 a 5 anos. (PNE. 2001/2010)

$\mathrm{Na}$ avaliação de sua execução constatou-se que a meta não foi, nem de longe, atingida e que a faixa etária de zero a 3 anos foi a que menos chegou perto de seu objetivo de expansão. É necessário destacar que a razão desse fato foi ter havido veto, pelo Presidente da República da época (Governo Fernando Henrique Cardoso II - 1999/2002), de todas as metas que implicavam em aumento do investimento de recursos públicos por parte do governo federal.

O II PNE 2014/2024 (Lei no 13.015/2014), discutido pelos sindicatos do magistério, associações científicas e movimentos sociais, por cerca de cinco anos, estabeleceu, em consequência, o mesmo percentual da meta do PNE anterior para a expansão das creches, ou seja

Universalizar, até 2016, a educação infantil na pré-escola para as crianças de 4 (quatro) a 5 (cinco) anos de idade e ampliar a oferta de educação infantil em creches de forma a atender, no mínimo, 50\% (cinquenta por cento) das crianças de até 3 (três) anos até o final da vigência deste PNE (PNE. Meta 1, 2014/2024). 
Estamos em 2017 e também constatamos que nenhuma das duas metas, seja em relação à creche ou à pré-escola, foi cumprida, mesmo a pré-escola sendo de matrícula obrigatória nos termos da EC 59/2009, pois cerca de 1,5 milhão de crianças ainda faltam para ser matriculadas nesta etapa de ensino.

Mas, evidentemente, muitas metas e estratégias do PNE 2014/2024 são a favor da expansão e universalização da educação básica, bem como da sua qualidade de ensino e a existência de um Plano Nacional sempre nos motiva para exigir que suas metas sejam cumpridas e que os governos façam dele, referência obrigatória para suas prioridades de atuação e investimento na educação.

Um dos aspectos importantes e inovador que o PNE 2014/2024 instituiu foi o Fórum Nacional de Educação (FNE), que tem como função o acompanhamento da execução do PNE, verificando a execução de suas metas e estratégias, e a realização de encontros nacionais, estaduais e municiais visando avaliar o PNE. Determina a lei que

\begin{abstract}
Art. 6o - A União promoverá a realização de pelo menos 2 (duas) conferências nacionais de educação até o final do decênio, precedidas de conferências distrital, municipais e estaduais, articuladas e coordenadas pelo Fórum Nacional de Educação, instituído nesta Lei, no âmbito do Ministério da Educação. $\int 1$ - O Fórum Nacional de Educação, além da atribuição referida no caput: I - Acompanhará a execução do PNE e o cumprimento de suas metas;

II - Promoverá a articulação das conferências nacionais de educação com as conferências regionais, estaduais e municipais que as precederem.

$\int 2 \mathrm{o}-$ As conferências nacionais de educação realizar-se-ão com intervalo de até 4 (quatro) anos entre elas, com o objetivo de avaliar a execução deste PNE e subsidiar a elaboração do plano nacional de educação para o decênio subsequente (FNE. 2014. Grifos nossos).
\end{abstract}

Infelizmente, o governo Temer, no mês de abril de 2017, por meio da Portaria MEC $\mathrm{n}^{\circ} 577$, destituiu membros das entidades sindicais, associações científicas e de movimentos sociais, inclusive seu presidente, indicados legitimamente pelas entidades, nomeando membros do próprio governo e de entidades privadas.

\title{
Retrocessos das políticas para a Educação Infantil
}

\section{Matricula obrigatória no ensino fundamental}

Um retrocesso indiscutível está presente em duas legislações: a Lei no.11.114/2005 que dispôs que as crianças deveriam ser matriculadas no ensino fundamental aos 6 anos de idades. No ano seguinte, a Lei no. 11.274/2006 tornou obrigatório o ensino fundamental de nove anos a partir dos seis anos de idade. Ou seja, aumentou-se um ano no ensino fundamental com a respectiva redução de um ano de atendimento na educação infantil. Esta Lei dispunha que, a partir de 2010, a matricula aos seis anos seria obrigatória para todas as crianças. A data de matrícula, relacionada ao dia de nascimento da criança gerou muitas discussões no país, pois algumas defendiam que a criança tivesse completado 6 anos, até o dia 31 de março e outros, até 30 junho. Algumas escolas privadas chegaram a defender a matrícula de crianças com 5 anos até o dia 31 de dezembro do ano da matrícula. A realidade é que, em muitos municípios e estados - e com apoio de parte da população - crianças veem sendo matriculadas com 5 anos de idade, antecipando seu processo de alfabetização sistemática. A defesa de tal medida baseava-se na alegação de 
que grande parte dos municípios ainda não tinha organizado a sua educação infantil, pois o FUNDEF política de fundos criada em 1996 e implementada em 1998 - havia municipalizado substantivamente o ensino fundamental, pois, conforme o discurso do governo, quanto mais alunos estivessem matriculados nesta etapa de ensino, o aporte de recursos seria mais significativo. Estabelecido o FUNDEB em 2006, não havia razão pedagógica política para tal antecipação, uma vez que alunos da educação infantil e do ensino fundamental teriam direito ao uso dos recursos do FUNDEB. Em 2009, a EC nº 59 tornou obrigatória a pré-escola para todas as crianças, portanto não restou razão novamente para tal antecipação. Alguns educadores defendiam essa antecipação esperando que os anos iniciais do ensino fundamental, ao receber crianças tão pequenas assumissem o lúdico, como método de trabalho e expandissem essa metodologia para as crianças até 10 anos de idade pelo menos. Tal não aconteceu. E a cada dia novas crianças de 5 anos são matriculadas no ensino fundamental perdendo a da oportunidade de continuarem crianças na educação infantil.

\section{Privatização da Educação Infantil}

Constata-se que a política nacional, estadual e municipal, frente à legislação econômica, em especial a EC no 19/1998 e a Lei Complementar no 101/2000 - Lei de Responsabilidade Fiscal (LRF), que estabeleceram os limites de 54\% das despesas totais com pessoal para o poder Executivo dos municípios (LRF, art. 20, item III/b), e 49\% para o dos estados (LRF, art. 20, item II/c), redefinindo as funções do estado, no sentido de desvincular o que for de interesse social ser realizado exclusivamente pelo Estado e legalizando a possibilidade de contratos de gestão com Organizações Não Governamentais (ONGs) ou empresas incentivou e legalizou a oferta do ensino público para ONGs e até transferências da gestão de escolas públicas, para Organizações Sociais (OS).

Em 2015, 40\% do atendimento em educação infantil era feito por atendimento privado e $60 \%$ do atendimento público, possuía convênio com entidades comunitárias, especialmente para o atendimento das crianças de zero a 3 anos. Infelizmente, constata-se que a tendência do atendimento em educação infantil, por meio da creche, continuará sendo via instituições particulares, comunitárias e filantrópicas. E com a recente aprovação da EC nº. 95/2016 a situação tende a se agravar e expandir.

\section{Governo Temer - aprovação da Emenda Constitucional no. 95, de 15/12/2016}

Os profissionais da educação não se deram conta, ainda, da gravidade das consequências da $\mathrm{EC} \mathrm{n}^{\circ}$. 95, que congela por 20 anos os investimentos nas áreas sociais, em especial, a da saúde e da educação (art. 101/ CF). Não se conhece experiência no mundo que tenha congelado por esse prazo os recursos de investimento social. Vinte exercícios financeiros correspondem ao prazo de dois PNEs de duração decenal!

Estudos realizados por entidades científicas e movimentos sociais (Fineduca e Campanha Nacional pelo Direito à Educação, 2016) mostram que em vinte anos, os 18\% de recursos de impostos constitucionalmente vinculados à manutenção e desenvolvimento do ensino terão se transformado, no máximo, em 10\%. Isso significa que nenhuma das metas previstas no PNE 2014/2024 para expansão e 
universalização da educação básica e superior, bem como as de valorização dos magistérios ou de qualidade de ensino, como a implantação do Custo-Aluno/ Qualidade (CAQ) ou o CustoAluno/Qualidade Inicial (CAQi) terão condições de ser implantadas.

Atente-se que a crise das universidades públicas federais e estaduais e as escolas de educação básica, com falta de pessoal devidamente formado, que já é grave, tenderá a ficar pior, uma vez que são vedados a criação de cargo, emprego ou função pública; alteração de estrutura de carreira; realização de concursos públicos; admissão ou contratação de pessoal a qualquer título, ressalvadas as reposições de cargo de chefia, de direção e os decorrentes de vacância de cargos efetivos, uma vez que tais providências implicam necessariamente em aumento de despesas, conforme exigência aprovada pela EC (art. 103/CF).

Com a perspectiva de mudanças radicais na Previdência Social, contra o direito dos trabalhadores, o movimento de aposentadorias voluntárias no magistério tem crescido de forma assustadora, o que deverá levar a uma nova crise trabalhista, em função das novas propostas de contrato de professores e especialistas extremamente precarizadas.

Pelas providências tomadas neste primeiro ano de governo fica evidente que um dos seus objetivos é a privatização acelerada do maior número de equipamentos da área social e das empresas públicas. Não por acaso, dentre outros bons exemplos, foram proibidas novas matrículas, em 2017, nas universidades públicas, mesmo existindo vagas ociosas nos campi das 17 universidades criadas no governo Lula II (2007/2010). Ao mesmo tempo, o valor dos recursos do Fundo de Financiamento Estudantil (FIES), um financiamento destinado a alunos das escolas superiores privadas, foi o maior desde a sua criação em 1999, estando hoje disponível cerca de R $\$ 19$ bilhões, um dos poucos recursos que não sofreu cortes.

\section{Inclusão da Educação Infantil na Base Nacional Comum Curricular (BNCC)}

Houve um equívoco por parte dos movimentos sociais e dos sindicados ligados ao magistério, em especial os da área da educação infantil, de não tentarem impedir a inclusão da educação infantil no documento da BNCC, pois, mesmo não havendo exigências legais na LDB para essa inclusão, nas versões I e II, iniciadas em 2013, a mesma foi incluída. É verdade que especialistas e pesquisadoras da área participaram de sua elaboração, preservando as características da educação infantil propostas nas Diretrizes Curriculares e garantindo que a BNCC seria orientada pelos campos de experiência educativa, concepção avançada de percursos metodológicos para ser utilizados nas escolas da infância (Barbosa; Richter, 2015).

A terceira versão, agora no Governo Temer, trazida a público dia 06 de abril de 2017 apresenta uma redução nas concepções de linguagens e de ensino-aprendizagem na educação infantil, contrariando totalmente as diretrizes curriculares desta etapa de ensino. Dividir a educação da primeira infância de zero a um ano e seis meses, e de um ano e sete meses a três anos, é um retrocesso à década de 60 , quando a psicologia comportamentalista dividia o desenvolvimento da criança em "estágios" de desenvolvimento. A Pedagogia das Competências, na $3^{\text {a }}$ versão da BNCC, retorna ao modelo dos parâmetros curriculares elaborados no final da década dos anos de 1990 e considerada superada por número significativo de especialistas europeus. A retirada dos conceitos de gênero e de orientação sexual, de uma das dez 
competências a serem promovidas nas escolas, expressa o retrocesso dessa concepção e a atuação de grupos religiosos em negociação direta com o governo para a retirada dessas questões.

Há um risco inclusive, de que a educação infantil seja considerada uma etapa escolarizante e preparatória para o ingresso no ensino fundamental. O que novamente contraria as novas concepções pedagógicas em defesa das crianças, expressas na Resolução CNE n. 05/2009.

\section{Projetos de Escola Sem Partido (ESP)}

Desde que o Governo Temer se apropriou do lema da bandeira brasileira "Ordem e Progresso", incorporada no seu programa de governo "Uma Ponte para o Futuro" ficou claro que não interessa a formação crítica dos alunos, nem da população, para que não sejam capazes de perceberem os movimentos reais de exploração dos trabalhadores e de perdas de direitos sociais no Brasil.

Os projetos do grupo ESP visam ao controle sistemático da atuação de professores e professoras, da educação infantil ao ensino superior, e em especial, da autonomia docente e escolar evitando e inibindo seu posicionamento crítico sobre quaisquer temas polêmicos. Ainda que haja pareceres do STF contrários a aprovação de leis que incorporem esta visão, na prática, perseguições e demissões de profissionais do magistério vêm acontecendo, com o objetivo de intimidar qualquer ação autônoma em seu âmbito, das escolas e docentes. Destaque-se a atuação desse grupo quando da aprovação de planos municipais, estaduais e nacional da educação condicionando a aprovação dos referidos planos à exclusão de questões de diversidade de gênero e sexual.

\section{Formação de professores e o ensino a distância (EAD)}

No Brasil a formação de professores da educação básica, via EAD, já é maior que nos cursos presenciais, mesmo se considerando somente a formação inicial desses profissionais, em especial os de educação infantil e dos anos iniciais do ensino fundamental. E há alterações danosas propostas aos cursos de licenciatura, uma vez que a BNCC deve "orientar os conteúdos desses cursos", portanto transformando os cursos de pedagogia em cursos que preparam o futuro professor/ professora para repetir em sala de aula os conteúdos - e só eles - previstos em cada ano dos anos iniciais do ensino fundamental e da educação infantil. Tem havido concordância, por parte do MEC, de redução significativa nas propostas de formação teórica desse profissional, uma vez que mudando sua função em sala de aula, de profissional proponente dos conteúdos, para "repetidor" de conteúdo pré-definido, não haverá necessidade de aprofundamento e diversificação na sua proposta pedagógica.

Sabe-se da situação ainda precária das professoras das creches comunitárias em todo país, parte delas sequer formadas em nível médio. O estímulo para a formação de professores em nível superior, em especial da educação infantil, vem se dando fundamentalmente por meio do ensino a distância. Ensino esse, que não sofre nenhum controle de qualidade por parte do Ministério da Educação, ao contrário, a Lei 13.415/2017 que (des)organizou o ensino médio incorpora profissionais não devidamente formados, sob a designação de "notório saber" e de formados em cursos de "complementação pedagógica". 
Agrava este fato, a transformação de parte significativa da formação teórica e dos fundamentos da educação, nos cursos presenciais privados de licenciatura, em ensino a distância, só se mantendo presenciais (ainda) as didáticas e metodologias de ensino.

\section{Uso de recursos do FUNDEB pelo setor privado}

A mesma Lei 13.415/2017 que (des)organizou o ensino médio autoriza o uso dos recursos do FUNDEB para parcerias com o setor privado, para a implantação do ensino médio integral e, apesar da divulgação de que se trata de investimento de "dinheiro novo", não é bem verdade, pois haverá uma redistribuição dos mesmos recursos que já são insuficientes para o atendimento público atual. Parte dos itinerários formativos (previstos no novo art. 36, da LDB) prometidos para o ensino médio, poderão ser realizados por empresas com o setor privado, por meio de parcerias, sem exigência de experiência prévia na área da formação prometida.

Observe-se o que dispõe a Lei 13.415, alterando o art. 36, da LDB:

$\int^{\circ} 11$. Para efeito de cumprimento das exigências curriculares do ensino médio, os sistemas de ensino poderão reconhecer competências e firmar convênios com instituições de educação a distância com notório reconhecimento, mediante as seguintes formas de comprovação: I - demonstração prática; II - experiência de trabalho supervisionado ou outra experiência adquirida fora do ambiente escolar; III - atividades de educação técnica oferecidas em outras instituições de ensino credenciadas; IV - cursos oferecidos por centros ou programas ocupacionais; V estudos realizados em instituições de ensino nacionais ou estrangeiras; VI - cursos realizados por meio de educação a distância ou educação presencial mediada por tecnologias (BRASIL. 2017. Grifos nossos).

\section{Programa Criança Feliz}

Um Programa retrógrado, lançado pelo governo Temer e sob responsabilidade da $1^{\mathrm{a}}$ dama é o Programa Criança Feliz, instituído pelo Decreto no 8.869, de 5 de outubro de 2016. Este Programa tem por objetivo: promover o desenvolvimento humano a partir do apoio e do acompanhamento do desenvolvimento infantil integral na primeira infância.

E como isso será feito? Informa o site do Ministério do Desenvolvimento Social e Agrário, visitado em 30 de agosto de 2017: "Por meio de visitas domiciliares às famílias participantes do Programa Bolsa Família, as equipes do Criança Feliz farão o acompanhamento e darão orientações importantes para fortalecer os vínculos familiares e comunitários e estimular o desenvolvimento infantil".

O site informa também que

"Os visitadores serão capacitados em diversas áreas de conhecimento, como saúde, educação, serviço social, direitos humanos, cultura etc. A troca com as famílias será rica e constante. Assim, novos campeões serão criados e a luta pelo desenvolvimento social será vencida. (BRASIL. 2016. grifos nossos).

O Programa autoriza que parcerias com órgãos e entidades públicas e privadas sejam firmadas para a execução do Programa (art. $9^{\circ}$ do Decreto).

É interessante lembrar que, no dia do lançamento desse Programa, o site do MEC, apresentava a $1^{\text {a }}$ dama vestida com um vestidinho azul, à semelhança de uma dedicada professora, personagem da 
novela "Carrossel”, que teve grande sucesso de público em um dos canais abertos da televisão brasileira. Neste dia, o site do Planalto, informava que "O Programa Criança Feliz serve para que essas crianças, principalmente das famílias mais carentes, tenham um acompanhamento adequado, conseguindo se desenvolver e criar boas raízes." (grifos nossos)

Essas informações nos permitem afirmar o quanto o governo atual está superado em relação às concepções de políticas públicas integradas para a $1^{\mathrm{a}}$ infância.

\section{PNAIC para a educação infantil}

Fomos surpreendidos com a Portaria MEC n 826, de 07 de julho de 2017, que "Dispõe sobre o Pacto Nacional pela Alfabetização na Idade Certa - PNAIC, suas ações, diretrizes gerais e a ação de formação no âmbito do Programa Novo Mais Educação - PNME” incorpora a pré-escola no Pacto Nacional de Alfabetização na Idade Certa (PNAIC), como pode ser constatado nos $\int 2^{\circ}$, do art. $2^{\circ}$ art. $6^{\circ}$, item I, letras "a" e "b", dentre outros:

$\int 2^{\circ}$ - As ações do PNAIC terão como foco os estudantes da pré-escola e do ensino fundamental, cabendo aos professores, coordenadores pedagógicos, gestores escolares e gestores públicos uma responsabilidade compartilhada no alcance do direito da criança de escrever, ler com fluência e dominar os fundamentos da Matemática no nível recomendável para sua idade. (grifos nossos)

Art. $6^{\circ}$ - As ações do PNAIC e do PNME compreendem os seguintes eixos:

I - Formação Continuada:

a) formação em serviço dos coordenadores pedagógicos da educação infantil, dos professores da pré-escola, dos coordenadores pedagógicos e professores do 10 ao 30 ano do ensino fundamental e de classes multisseriadas que possuem alunos desses anos, dos articuladores e mediadores de aprendizagem das escolas das redes públicas de ensino participantes do PNME;

b) formação e constituição de uma rede de formadores para a pré-escola e educação infantil, para o 10 ao 30 ano do ensino fundamental e para o PNME; (...) (BRASIL. PNAIC. 2017. Grifos nossos).

Essa Portaria repete praticamente toda a sistemática do PNAIC do governo anterior, agora incluindo a pré-escola e a educação infantil. É avassalador o movimento do governo Temer no sentido de destruir e deturpar as conquistas da educação infantil em todo o país. Espera-se que o Movimento Interfóruns de Educação Infantil do Brasil (MIEIB), os sindicatos do magistério, as associações científicas se unam em defesa da educação infantil e das Diretrizes Nacionais expressas na Resolução CNE/CEB n ${ }^{\circ}$ 05/2009, para resguardar o direito à infância das nossas crianças brasileiras, recusando-se a aceitar essa formação ou contribuir para que ela aconteça.

\section{Considerações Finais}

Nesse momento dramático que estamos vivendo no país, mais que nunca a união é fundamental para podermos recolocar as ações e os direitos em seus devidos lugares, em especial, os objetivos e o papel da educação infantil no desenvolvimento saudável de nossas crianças. Assim, temos que nos organizar para garantir e lutar pela

1) Não incorporação do processo de alfabetização e letramento na pré-escola e em toda educação infantil; 
2) Defesa intransigente do lúdico na educação infantil;

3) Resistência à aplicação de testes estatísticos para "medir a qualidade" da educação infantil;

4) Construção de projetos pedagógicos que atendam as crianças pequenas no conjunto de suas necessidades psicológicas, culturais, emocionais e educacionais;

5) Formação consistente teórica e prática dos e das professoras de educação infantil, que lhes permitam a escolha de métodos diferenciados e coerentes para a infância;

6) Condição de dignidade de trabalho e de salário dos e das profissionais da educação brasileira, que vêm sendo desvalorizados sistematicamente.

Se esses seis compromissos forem pautados por todos e todas que trabalham e atuam na educação e formação da educação infantil, talvez a gente possa resguardar e proteger os avanços pedagógicos e educacionais construídos historicamente pelo conjunto das instituições educacionais que trabalham com a $1^{a}$ infância, no seu direito de brincar, de produzir cultura, de exercitar sua curiosidade, de experimentar diversas linguagens, de ser feliz.

Como diz F. Nietzsche "E aqueles que foram vistos dançando foram julgados insanos por aqueles que não podiam escutar a música".

Que nos mantenhamos dançando no ritmo coerente de nossa "música" e de nossas convicções, como forma de resistência às tentativas de destruição da formação humanista, ética e estética de nossas crianças.

\section{Referências}

BRASIL. Constituição (1998). Constituição da República Federativa do Brasil. Artigo 227. Brasília, DF: Senado Federal: Centro Gráfico, 1988.Disponível em: www.planalto.gov.br/ccivil_03/constituicao/constituicaocompilado.htm. Acesso em 23 ago. 2017.

. Constituição (1988). EMENDA CONSTITUCIONAL nº 53. 2006.Disponível em: www.planalto.gov.br/ccivil_03/constituicao/constituicaocompilado.htm. Acesso em 23 ago. 2017.

. Constituição (1988). EMENDA CONSTITUCIONAL nº 59.Mudança de redação do art. 214 da Constituição Federal de 1988 e acréscimo do item VI. 2009. De 11 de novembro de 2009.Disponível em: www.planalto.gov.br/ccivil 03/constituicao/constituicaocompilado.htm. Acesso em 26 ago. 2017. . Constituição (1988).EMENDA CONSTITUCIONAL nº 14.Modifica os artigos 34, 208, 211 e 212 da Constituição Federal e dá nova redação ao artigo 60 do Ato das Disposições Constitucionais Transitórias. De 12 de setembro de 1996. Disponível em: www.planalto.gov.br/ccivil_03/constituicao/constituicaocompilado.htm. Acesso em 23 ago. 2017. 
Constituição (1988). EMENDA CONSTITUCIONAL $\mathbf{n}^{\mathbf{0}} \mathbf{9 5}$, de 15 de dezembro de 2016.Disponível em: www.planalto.gov.br/ccivil 03/constituicao/constituicaocompilado.htm. Acesso em 30 ago. 2017.

Constituição (1988). EMENDA CONSTITUCIONAL no 19, de 4 de junho de 1998.Disponível em: www.planalto.gov.br/ccivil_03/constituicao/constituicaocompilado.htm. Acesso em 23 ago. 2017.

BRASIL. Estatuto da Criança e do Adolescente (ECA). Lei Federal 8069 de 13/07/1990. Disponível em:www.planalto.gov.br/ccivil_03/leis/L8069.htm. Acesso em 19 de ago. 2017.

BRASIL.Lei de Diretrizes e Bases da Educação Nacional. Lei no 9.394/96,artigo 62, de 20 de dezembro de 1996.Disponível em:www.mec.gov.br/legislacao. Acesso em 26 ago. 2017.

BRASIL. Lein ${ }^{\circ}$ 13.257, de 8 de março de 2016.Disponível em: www.planalto.gov.br/ccivil 03/leis/L8069.htm. Acesso em 19 de ago. 2017.

BRASIL. Lei $\mathbf{n}^{\circ}$ 11.114, de 16 demaio de 2005. Disponível em: www.planalto.gov.br/ccivil 03/leis/L8069.htm. Acesso em 19 de ago. 2017.

BRASIL. Lei no. 11.274, de 06 de fevereiro de 2006.Disponível em: www.planalto.gov.br/ccivil_03/leis/L8069.htm. Acesso em 19 de ago. 2017.

BRASIL. Lei 13.415/2017, de 06 de fevereiro de 2017.Disponível em:

www.planalto.gov.br/ccivil 03/leis/L8069.htm. Acesso em 21 de ago. 2017.

BRASIL.Lei $\mathbf{n}^{\mathbf{0}}$. 11.738, de 16 de julho de 2008. Disponível em:www.planalto.gov.br/ccivil 03/leis/L8069.htm. Acesso em 19 de ago. 2017.

BRASIL. Lei Complementar $\mathbf{n}^{\mathbf{0}}$. 101.Lei de Responsabilidade Fiscal (LRF), de 04 de maio de 2.000. Estabelece normas de finanças públicas voltadas para a responsabilidade na gestão fiscal e dá outras providências. Disponível em:www.planalto.gov.br/ccivil 03/leis/L8069.htm. Acesso em 21 de ago. 2017 BRASIL.Lei no 10.172/2001. Plano Nacional de Educação, 2001/2010.Disponível em:www.planalto.gov.br/ccivil_03/leis/L8069.htm. Acesso em 19 de ago. 2017.

Lei no 13.015/2014. Plano Nacional de Educação, 2014/2024.Disponível em:www.planalto.gov.br/ccivil_03/leis/L8069.htm. Acesso em 19 de ago. 2017. 
BRASIL. Decreto no 8.869/2016, institui o Programa Criança Feliz. De 5 de outubro de 2016.Disponível em:www.planalto.gov.br/ccivil 03/ ato2015-2018/2016/decreto/D8869.htm. Acesso em 30 de ago.2017.

BRASIL.Ministério da Educação.Portaria no 577, de 27 de abril de 2017.Disponível em:www.mec.gov.br/legislacao. Acesso em 26 ago. 2017.

Ministério da Educação. Portaria n ${ }^{\circ}$ 826, que "Dispõe sobre o Pacto Nacional pela Alfabetização na Idade Certa - PNAIC, suas ações, diretrizes gerais e a ação de formação no âmbito do Programa Novo Mais Educação - PNME.De 07 de julho de 2017.Disponível em:www.mec.gov.br/legislacao. Acesso em 26 ago. 2017.

BRASIL. Ministério da Educação. FÓRUM NACIONAL DE EDUCAÇÃO. Portaria n. ${ }^{\circ}$ 1.407, de 14 de dezembro de 2010, publicada no Diário Oficial da União de 16 de dezembro de 2010, Plano Nacional de Educação. pela Lei 13.005, de 24 de junho de 2014. Disponível em:www.mec.gov.br/legislacao. Acesso em 29 ago. 2017.

\section{BRASIL. Ministério da Educação (MEC)/ Instituto Nacional de Estudos e Pesquisas}

Educacionais Anísio Teixeira (INEP).Sinopses Estatísticas da Educação Básica (2001/2007/2015).

Disponível em: http://inep.gov.br/sinopses-estatisticas-da-educacao-basica. Acesso em 20.08.2017.

BRASIL. Ministério da Educação (MEC). Terceira versão da Base Nacional Comum Curricular

(BNCC). 2017. Disponível em: http://basenacionalcomum.mec.gov.br/images/BNCC_publicacao.pdf. Acesso em 15.08.17

BRASIL. Conselho Nacional de Educação (CNE/CBE).Parecer nº 20, Revisão das Diretrizes Curriculares Nacionais para a Educação Infantil. 11 de novembro de 2009. Disponível em portal.mec.gov.br > Conselho Nacional de Educação. Acesso em 29 de ago. 2017.

Resolução CNE/CEBn ${ }^{\circ}$ 5, de 17de dezembro de 2009. Fixa as Diretrizes Curriculares Nacionais para a Educação Infantil. 2009.Disponível em portal.mec.gov.br > Conselho Nacional de Educação. Acesso em 29 de ago. 2017.

BARBOSA, M. C. S. B.; RICHTER, S. R.S. Campos de Experiência: uma oportunidade de interrogar o currículo, in (Org.) Finco, D; Barbosa, M. C.; Faria, A. L. G. de; Campos de Experiências na escola da infância; Leitura Crítica, Campinas/SP, 2015. 
Instituto Brasileiro de Geografia e Estatística. IBGE.Estimativas populacionais para os municípios e para as Unidades da Federação brasileiros em 2017. Disponível em

http://cidades.ibge.gov.br/xtras/temas.php?.codmun=0\&idtema=130. Acesso em 05.08.17.

NOTA TÉCNICA. Nota Conjunta Fineduca e Campanha (2016): a aprovação da PEC 241 significa estrangular a educação pública brasileira e tornar letra morta o Plano Nacional de Educação 2014-2024. Disponível em: https://undime.org.br/noticia/18-10-2016-14-38-nota-conjunta-fineduca-e-campanha-aaprovacao-da-pec-241-significa-estrangular-a-educacao-publica-brasileira-e-tornar-letra-morta-o-planonacional-de-educacao-2014-2024 Acesso em: 21.08.2017.

NIETZSCHE, F. Assim Falou Zaratustra. Um Livro para Todos e para Ninguém. Ed. Vozes. São Paulo.2002.

SÃO PAULO. PME - Plano Municipal de Educação da Cidade de São Paulo - Parecer final aprovado em novembro de 2014 pela Comissão de Educação, Cultura e esportes da Câmara Municipal de São Paulo sobre o PL nº. 415/2012 e projeto substitutivo. Relatoria Vereador Toninho Vespoli - PSOL. São Paulo; junho de 2015. 